\title{
Mandarin Chinese sentence final $d e$ as a marker of private evidence
}

\author{
Hooi Ling Soh*
}

\begin{abstract}
In this paper, I present new empirical observations regarding discourse restrictions and interpretative effects associated with Mandarin Chinese sentence final $d e$ in a bare $d e$ sentence. I propose an analysis of $d e$ as a discourse marker that marks "private evidence". I then consider a prediction of the analysis regarding the distribution of $d e$ in yes/no questions. I show that the pattern of restrictions observed with de in yes/no questions follows from the proposed analysis, coupled with a specific proposal about the syntax of $d e$, and certain standard assumptions about the syntax of yes/no questions and modal auxiliaries. Specifically, I argue that de heads a projection below TP and above a modal projection for non-epistemic modals. I then discuss apparent counter-examples to the proposed discourse restrictions and suggest that the apparent counter-examples are not bare de sentences, but rather shi...de sentences with a silent shi. The proposed analysis has implications on the syntax of modal auxiliaries, the relation between bare de sentences and shi...de sentences, and the syntax of discourse particles. It connects de with discourse particles that mark the speaker's belief about whether the (evidence for the) asserted proposition is shared knowledge between the speaker and the hearer and whether the (evidence for the) proposition is "verifiable on the spot" (e.g., German ja (Kratzer 1999, 2004; Gutzmann 2009); English parenthetical I'm telling you (Reese and Soh 2018)).
\end{abstract}

Keywords. Sentence final de; bare de sentences; shi...de sentences; discourse particles; private evidence; yes-no questions; epistemic modals; non-epistemic modals

1. Introduction. Previous studies on Mandarin sentence final de have mainly focused on constructions where de appears with the copula/focus marker shi, which are often referred to as the shi...de constructions (Simpson and Wu 2002, Paul and Whitman 2008, Cheng 2008, Hole 2011). The shi...de constructions are cleft-like in that they put a particular constituent in focus.

(1) ta shi lai zhao wo de. Shi...de sentence s/he FOC come look.for me DE 'It is (the case) that s/he came to look for me.'

The appearance of $d e$ in bare de sentences has not received exclusive focus partly because its contribution in such sentences is elusive (e.g., Cheng (2008) analyzes de in a bare de sentence as

\footnotetext{
* I would like to thank Brian Reese and Hanlin Zhu for extensive discussions. Many thanks to my native speaker consultants for their patience and care with the data. The current project received support from the Chiang ChingKuo Foundation for International Scholarly Exchange (Scholar Grant for Professors, 2016-2017), and an Imagine Fund Annual Award from the University of Minnesota, which I gratefully acknowledge. Hooi Ling Soh, University of Minnesota (sohxx001@umn.edu).
} 
an assertion operator that relates to sentential emphasis/focus).

(2) ta lai zhao wo de. Bare de sentence
s/he come look.for me DE
'S/he came to look for me.'

A significant challenge for determining the contribution of de concerns how bare de sentences are related to shi...de sentences. Adding to the challenge is the intuition that there is a variant of shi...de sentences with a silent (or omitted) shi as in (3) (Li and Thompson 1981; Hole 2011).

(3) ta shi lai zhao wo de. Shi...de sentence (with a silent shi) $\mathrm{s}$ /he FOC come look.for me DE 'It is (the case) that s/he came to look for me.'

Some previous authors assume without argument that bare de sentences are shi...de sentences with a silent shi (e.g., Hole (2011)). On the other hand, Cheng (2008) argues that bare de sentences are distinct from shi...de sentences.

In this paper, I present a novel observation about a restriction in the use of $d e$ in bare de sentences. Specifically, de is infelicitous in utterance contexts where the evidence for the asserted proposition is shared between the speaker and the addressee, or is readily available in the utterance context. I propose that de marks the speaker's belief that the status of the evidence for the asserted proposition is private at utterance time, with private defined using the notion of accessibility:

(4) Private evidence: Evidence for a proposition that is accessible to the speaker and not the addressee

(5) Accessibility: An individual has access to his own knowledge base and readily available evidence in the utterance context

I show how the proposed analysis accounts for the discourse restrictions as well as interpretive effects associated with $d e$ in a bare de sentence. I then consider a prediction of the analysis regarding the distribution of $d e$ in yes/no questions. I show that the pattern of restrictions observed with de in yes/no questions follows from the proposed analysis, coupled with a specific proposal about the syntax of $d e$, and certain standard assumptions about the syntax of yes/no questions and modal auxiliaries. Specifically, I claim that de heads a projection below TP and above a modal projection for non-epistemic modals. I then discuss apparent counter-examples to the discourse restrictions and suggest that they are not bare de sentences, but rather shi...de sentences with a silent shi. Finally, I discuss implications of the analysis on the syntax of modal auxiliaries, the relation between bare de sentences and shi...de sentences and the syntax of discourse particles. The current proposal connects Mandarin sentence final de with German discourse particle ja (Kratzer 1999, 2004; Gutzmann 2009) and English parenthetical I'm telling you (Reese and Soh 2018). The semantics of these particles/expressions make reference to the speaker's belief about whether the (evidence for the) asserted proposition is shared knowledge between the speaker and the hearer and whether the (evidence for the) proposition is "verifiable on the spot". 
2. Discourse restrictions and interpretive effects of sentence final $\boldsymbol{d e}$. The felicity of the use of de depends on two factors: (i) whether or not the evidence for the asserted proposition is shared between the speaker and the addressee and (ii) whether the evidence is readily available in the utterance context.

2.1. ASSERTION BASED ON EVIDENCE KNOWN TO THE SPEAKER AND THE ADDRESSEE. Assertions based on evidence known to both the speaker and the addressee are infelicitous with de. Assertions based on sensory experiences in the utterance context that are necessarily shared by the speaker and the addressee provide clear examples of this restriction in the use of $d e$. Consider the context in (6).

(6) Context: The speaker and the addressee are visiting a tropical island for the first time and when they arrive, the weather is hot.
a. zhe-li hen re.
here very hot
'It's hot here.'
b. \#zhe-li hen re de.
here very hot DE
'I'm telling you, it's hot here.'

The speaker may utter (6a) felicitously to comment on the condition of the weather, but not (6b).

\subsection{ASSERTIONS BASED ON EVIDENCE KNOWN TO THE SPEAKER BUT NOT THE ADDRESSEE.}

Assertions based on evidence known to the speaker but not the addressee are in general felicitous with de. Consider the context in (7).

(7) Context: The speaker knows that the girl standing across the room has a boyfriend, and believes that the addressee does not know that.
a. ta you nan-peng-you.
3SG have boyfriend
'She has a boyfriend.'
b. ta you nan-peng-you de.
3SG have boyfriend DE
'I'm telling you, she has a boyfriend.'

The speaker may utter either (7a) or (7b) felicitously to let the addressee know that the girl has a boyfriend. However, (7a) and (7b) have different discourse effects: (7a) serves as a neutral statement of fact, while (7b) is considered an advice or warning.

\subsection{ASSERTIONS BASED ON EVIDENCE READILY AVAILABLE IN THE UTTERANCE CONTEXT. Some assertions based on evidence known to the speaker but not the addressee are nevertheless infelicitous with $d e$. These assertions involve evidence that is readily available in the utterance context. They are readily available in the sense that minimal effort is required for the addressee to access the information. Because evidence readily available in the utterance context is sensory in nature or has a sensory component, assertions based on sensory experience provide clear}


examples to illustrate this restriction. Consider the context in (8).

(8) Context: The speaker and the addressee are at a party facing each other. The speaker can see Ling-ling's boyfriend, who is somewhere behind the addressee.

a. Ling-ling de nan-peng-you zai zhe.

Ling-ling POss boyfriend at here

'Ling-ling's boyfriend is here.'

b. \#Ling-ling de nan-peng-you zai zhe de.

Ling-ling POSS boyfriend at here DE

'I'm telling you, Ling-ling's boyfriend is here.'

The speaker may utter (8a) felicitously to express the idea that Ling-ling's boyfriend is here, but not ( $8 \mathrm{~b})$. The evidence is considered "readily available" in that the effort required to access the information is minimal: the addressee only needs to turn his/her head to access the relevant evidence.

2.4. Summary. A bare de sentence is infelicitous in utterance contexts where the evidence for the asserted proposition is shared between the speaker and the addressee, or is readily available in the utterance context. The use of $d e$ in a bare $d e$ sentence is sometimes associated with the speaker's intention to "offer advice or warning" or to "encourage the addressee to partake in a certain activity on the basis of the speaker's personal experience".

3. Accounting for discourse restrictions and interpretive effects of sentence final de. To account for the discourse restrictions and interpretive effects of sentence final de, I present an analysis of $d e$ as a discourse marker, marking private evidence, as elaborated in (9).

(9) Sentence final $d e$ (in a bare $d e$ sentence) marks the speaker's belief that the status of the evidence for the asserted proposition is private at utterance time.

Private evidence: Evidence for a proposition that is accessible to the speaker and not the addressee

Accessibility: An individual has access to his own knowledge base and readily available evidence in the utterance context

The interpretive effects of de relating to the speaker's intention to "offer advice or warning" or to "encourage the addressee to partake in a certain activity on the basis of the speaker's personal experience" follow naturally from the proposed analysis. Although it is generally the case that the speaker offers information that $\mathrm{s} / \mathrm{he}$ believes the addressee does not know when making an assertion, this is not always the case. A speaker may felicitously assert a proposition that $\mathrm{s} / \mathrm{he}$ has a reasonable belief that the addressee knows as well. For example, the utterance in (10) is felicitous in the specified context, even though the speaker can reasonably assume that both $\mathrm{s} / \mathrm{he}$ and the addressee experience the weather as being hot. 
(10) Context: The speaker and the addressee are visiting a tropical island. The weather is hot. zhe-li hen re.

here very hot

'It's hot here.'

This is because what a speaker asserts is taken as proposals to change the common ground, with the goal of having all discourse participants accept the relevant proposition for the purpose of the conversation (Stalnaker 1999: 86). There is no requirement for the proposition to be unknown to the addressee. ${ }^{1}$ On the other hand, advice/warning and encouragements to partake in a certain activity on the basis of a personal experience are usually offered in contexts in which the speaker believes that $\mathrm{s} /$ he knows something that the addressee does not. Because the use of de explicitly marks the evidence for the asserted proposition as being not accessible to the addressee, it is natural to associate the discourse function of such utterances to offering advice/warning or encouragements.

4. Sentence final $\boldsymbol{d e}$ in yes/no questions. The proposed analysis predicts that $d e$ has restricted distribution in questions. Specifically, de may not have a question operator within its scope. This is because de marks the nature of the speaker's evidence for the truth of a certain proposition within its scope. Questions are neither true nor false, and it is unclear what evidence for a question means.

I consider this predication in yes/no questions. Mandarin Chinese has two main types of yes-no questions: (i) A-not A questions and (ii) ma-questions. A-not-A questions are formed by the reduplication of a verbal element (e.g., verb, preposition, auxiliary) and the insertion of a negative morpheme $b u$ (or $m e i$ ) between the reduplicated form. An example is given below:

(11) ta lai-bu-lai zhao ni?

$3 \mathrm{SG}$ come-not-come look.for $2 \mathrm{SG}$

'Is he coming to look for you?'

$M a$-questions are formed with the sentence final question particle $m a$, as in (12).

(12) ta lai zhao ni ma?

3SG come look.for $2 \mathrm{SG}$ Q

'Did he come to look for you?'

I show in the following subsections that sentence final $d e$ is compatible with some yes/no questions but not others. In particular, A-not-A questions involving reduplicated verbs, prepositions and non-epistemic modal auxiliaries are incompatible with de, while $m a$-questions and A-not-A questions involving reduplicated dummy auxiliary shi 'be' and epistemic modal auxiliaries are compatible with $d e$.

4.1. The PATtern Of Restrictions. De is not compatible with A-not-A questions involving a

${ }^{1}$ Common ground: It is common ground that $\varphi$ in a group if all members accept (for the purpose of the conversation) that $\varphi$, and all believe that all accept that $\varphi$, and all believe that all believe that all accept that $\varphi$, etc. (Stalnaker $2002: 716)$ 
reduplicated verb or preposition, as shown below:

(13)

a. ta lai-bu-lai zhao ni?

3SG come-not-come look.for $2 \mathrm{SG}$

'Is he coming to look for you?'

b. *ta lai-bu-lai zhao ni de?

3SG come-not-come look.for 2SG DE

(14) a. ta zai-bu-zai jia?

3sG at-not-at home

'Is s/he at home?'

b. *ta zai-bu-zai jia de?

3SG at-not-at home DE

It is also incompatible with A-not-A questions formed with a reduplicated non-epistemic modal such as hui 'will, can (ability)', keyi 'can (permission, ability)' and neng 'can (ability)'.

(15) a. ta hui-bu-hui shuo fayu?

3SG can-not-can speak French

'Can s/he speak French?'

b. *ta hui-bu-hui shuo fayu de?

3SG can-not-can speak French DE

(16) a. ta hui-bu-hui bang ta?

3SG will-not-will help 3SG

'Will s/he help him/her?'

b. *ta hui-bu-hui bang ta de?

3SG will-not-will help 3SG DE

(17) a. ta ke-bu-keyi wan hui jia?

3SG can-not-can late return home

'Can he come home late?'

b. *ta ke-bu-keyi wan hui jia de?

3SG can-not-can late return home DE

(18) a. ta neng-bu-neng anjing-de zuo yi-zheng-ge xiawu?

3SG can-not-can quietly-MOD sit one-whole-CL afternoon

'Can he sit quietly for the whole afternoon?'

b. *ta neng-bu-neng anjing-de zuo yi-zheng-ge xiawu de?

3SG can-not-can quietly-MOD sit one-whole-CL afternoon DE

On the other hand, de can appear in ma-questions (Cheng 2008). ${ }^{2}$ An example is given below:

${ }^{2}$ Cheng (2008) shows that sentence final de may not appear in A-not-A questions and wh-questions, but may appear in yes-no questions formed by the question particle $m a$. It is noted that the contrast in their behaviors is related to the relative scope of the question operator in relation to $d e$. I leave aside the distribution of $d e$ in wh-questions as 

a. ta lai zhao ni ma?
3SG come look.for 2SG Q
'Did he come to look for you?'
b. ta lai zhao ni de ma?
3SG come look.for $2 \mathrm{SG}$ DE Q
'Did he come to look for you?'

It may also appear with A-not-A question involving reduplicated shi 'be' and reduplicated epistemic modal auxiliary hui 'could (possibility)'.

(20) a. ta shi-bu-shi lai zhao ni?

3SG be-not-be come look.for $2 \mathrm{SG}$

'Did he come to look for you?'

b. ta shi-bu-shi lai zhao ni de?

3SG be-not-be come look.for 2SG DE

'Did he come to look for you?'

(21) a. ta hui-bu-hui wan-quan bu zhidao?

3SG could-not-could completely not know

'Could s/he be completely unaware (of it)?'

b. ta hui-bu-hui wan-quan bu zhidao de?

3SG could-not-could completely not know DE

'Could s/he be completely unaware (of it)?'

In addition to the pre-verbal position, both the A-not-A form of shi and epistemic modal hui can appear in a sentence initial position. Note that de is compatible with A-not-A questions with sentence initial shi and epistemic modal hui as well.

(22) a. shi-bu-shi ta lai zhao ni?

be-not-be 3SG come look.for 2SG

'Did he come to look for you?'

b. shi-bu-shi ta lai zhao ni de?

be-not-be 3SG come look.for 2SG DE

'Did he come to look for you?'

(23) a. hui-bu-hui ta wan-quan bu zhidao?

could-not-could 3SG completely not know

'Could s/he be completely unaware (of it)?'

b. hui-bu-hui ta wan-quan bu zhidao de?

could-not-could 3sG completely not know DE

'Could s/he be completely unaware (of it)?'

4.2. THE SYNTAX OF DE. In this section, I show that the pattern of restrictions observed with de

judgments are variable for reasons unclear to me at this point, and follow Cheng (2008) in pursuing an explanation in terms of the relative scope of the question operator in relation to de. 
in yes/no questions follows from the proposed analysis, coupled with a specific proposal about the syntax of $d e$, and certain standard assumptions about the syntax of yes/no questions and modal auxiliaries (cf. Cheng 2008). I assume that epistemic modals appear structurally higher than non-epistemic modals (Cinque 1999; Tsai 2015). In particular, I assume that Mandarin epistemic modals may head a projection above TP, namely $\operatorname{Mod}^{\mathrm{E}} \mathrm{P}$ (Tsai 2015). In addition, I assume that they may also appear in T. Specifically, while sentence initial epistemic modals appear in $\mathrm{Mod}^{\mathrm{E}}$, pre-verbal epistemic modals appear in T. On the other hand, I assume that nonepistemic modals appear in a projection lower than TP and above vP, namely Mod $^{\mathrm{NE}}$ (cf. Tsai 2015).

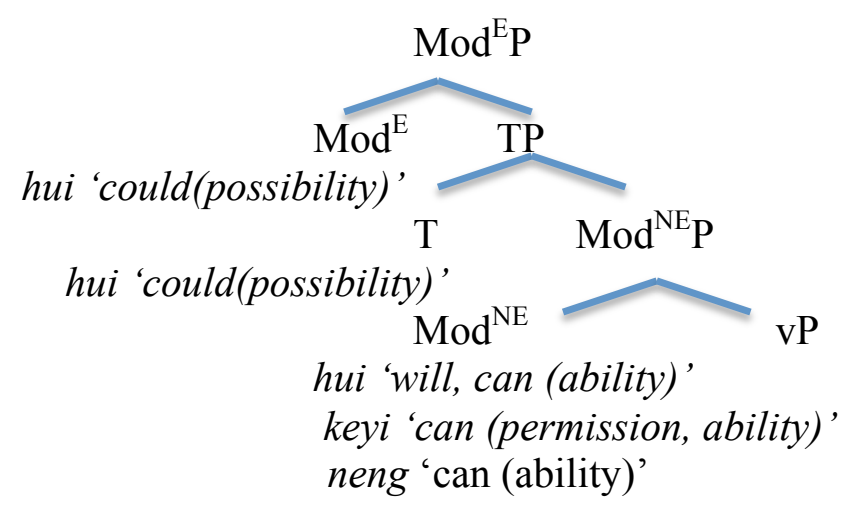

I assume that the auxiliary shi occupies a structurally higher position than other auxiliaries such as neng 'can' and hui 'will' (Soh 2007). I assume that pre-verbal shi appears in T and sentence initial shi appears in $\operatorname{Mod}^{\mathrm{E}}$, both occupying positions higher than $\operatorname{Mod}^{\mathrm{NE}}$.

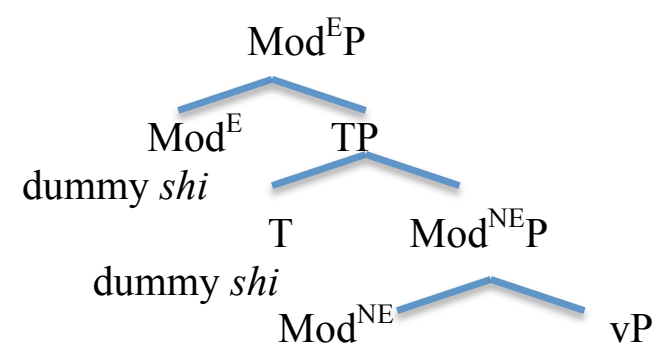

As for $m a$-questions, I assume that the question marker $m a$ is in C (Cheng 1991; Paul 2015), and it has scope over $\operatorname{Mod}^{\mathrm{E}} \mathrm{P}$.

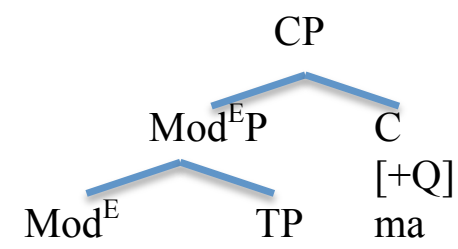

For A-not-A questions, I assume that an A-not-A question contains a $[+\mathrm{Q}]$ feature that raises to the CP domain (at LF) (Huang 1982, 1988; Ernst 1994). As shown in (27), the [+Q] feature is generated in the same position where the A-not-A form is found (Ernst 1994; Soh and Gao 2006; cf. Law 2006; J.W. Lin 1992), and I assume that the scope of the yes-no question is the node 
immediately dominating the A-not-A form (Ernst 1994; Soh and Gao 2006).

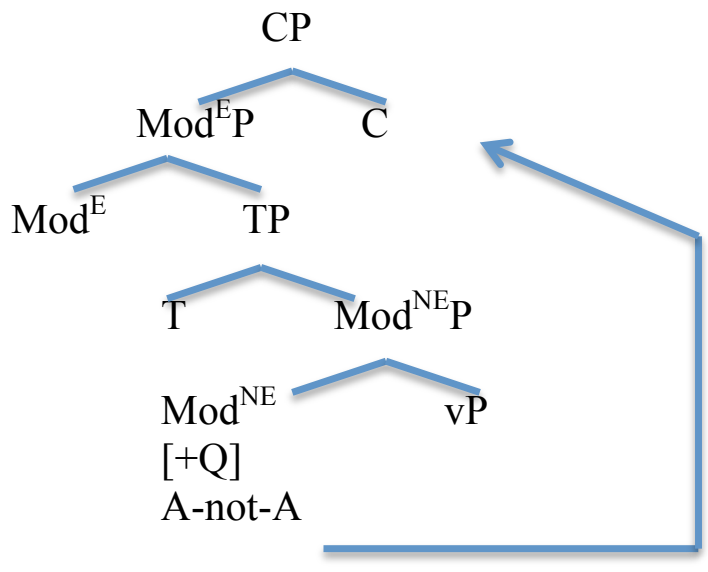

I propose that $d e$ heads a projection between TP and $\operatorname{Mod}^{\mathrm{NE}} \mathrm{P}$ (cf. Cheng 2008). ${ }^{3}$

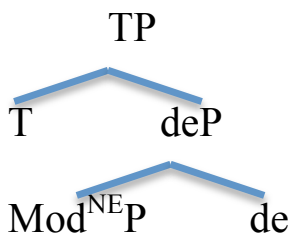

The account is straightforward. Sentence final de cannot appear in A-not-A questions involving reduplicated verbs, prepositions and non-epistemic modal auxiliaries (e.g., hui 'will, can (ability)', keyi 'can (permission, ability)', neng 'can (ability)') because it would scope over the $[+\mathrm{Q}]$ feature associated with the A-not-A form of these questions. ${ }^{4}$ For example, (29) shows the structure of an A-not-A question with a reduplicated non-epistemic modal. The structure is ruled out because $d e$ scopes over the $[+\mathrm{Q}]$ feature in $\mathrm{Mod}^{\mathrm{NE}}$.

\footnotetext{
${ }^{3}$ Cheng (2008) proposes that $d e$ in a bare de sentence is associated with the presence of an assertion operator that takes a proposition as its argument. It is noted that de may be the head of the AssertionP, which hosts the assertion operator. Most other studies on the syntax of de focus exclusively on shi...de sentences, which I assume to be distinct from bare de sentences. See for example Simpson and Wu (2002), Paul and Whitman (2008), Hole (2011), Paul (2014) and Song (2015).

${ }^{4}$ See Ernst (1994) for the incompatibility of certain adjuncts (e.g., yiding 'definitely') with certain A-not-A questions in Mandarin Chinese, analyzed in terms of these adverbs not being able have a question operator within its scope.

(i) *ta yiding qu-bu-qu?

3SG definitenly go-not-go

'Is he definitely going?'

See Law (2006) for an alternative analysis. The incompatibility of $d e$ with questions may be related to the observation that some speaker-oriented adverbs are not compatible with questions (Ernst 2009).
} 


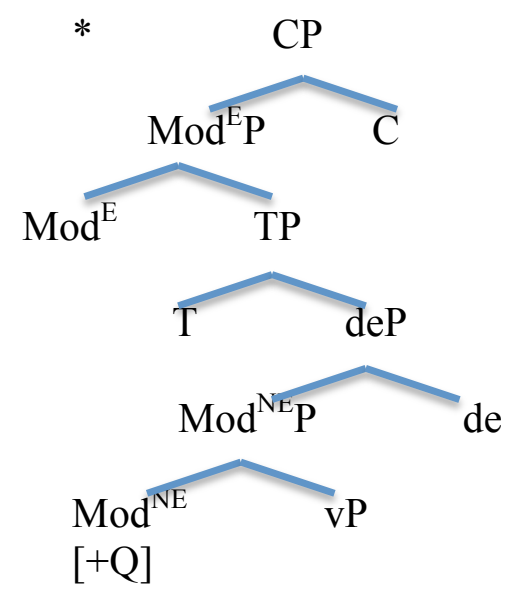

A-not-A

On the other hand, $d e$ can appear in $m a$-questions and A-not-A questions involving reduplicated dummy auxiliary shi 'be' and epistemic modal auxiliary hui 'could (possibility)' since the [+Q] feature associated with these questions are above $d e$. For example, consider the structure of an A-not-A question formed with an epistemic modal in T, given in (30). The structure is acceptable as the $[+\mathrm{Q}]$ feature is outside the scope of $d e$.

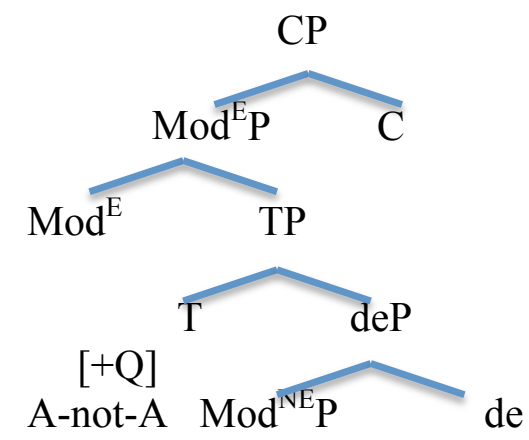

As in the case when $d e$ is used in statements, the acceptable use of $d e$ in questions marks the speaker's belief that $\mathrm{s} /$ he has private evidence for the relevant proposition (e.g., hearsay evidence). For example, in the context given in (31), the speaker may use either (31a) or (31b) to ask whether Ling-ling's boyfriend is at the party.

(31) Context: The speaker and the addressee are at a party.

a. Ling-ling de nan-peng-you zai zhe ma?

Ling-ling POss boyfriend at here Q

'Is Ling-ling's boyfriend here?'

b. Ling-ling de nan-peng-you zai zhe de ma?

Ling-ling POSS boyfriend at here DE Q

'Is Ling-ling's boyfriend here?'

(31a) is a neutral question, while (31b) is associated with an implication that the speaker has reason to think that Ling-ling's boyfriend is at the party (e.g., someone had mentioned to the speaker that Ling-ling's boyfriend would be at the party). 
5. Apparent counter-examples and shi...de sentences. It is important to note that there are cases where a bare de appears to be used in contexts where the evidence for the asserted proposition is accessible to the addressee, contrary to expectation. These cases involve a prior discussion of the relevant proposition and the use of $d e$ serves to confirm the relevant proposition in response to a contrary view or doubt held by the addressee. I refer to these cases as "confirmation" cases. An example is given in (32).

(32) Context: A is looking for his watch. B indicated that he believed that the watch was in the room (where they are), but A expressed doubt about that and thought that he might have left it somewhere else.

B: (upon finding the watch) kan! shou-biao zai zhe de. look watch at here DE 'Look, the watch is here.'

The discourse effect of $d e$ in confirmation cases are similar to that of (shi)...de constructions which according to Li and Thompson (1981: 589) serve "to characterize or explain a situation by affirming or denying some supposition, as opposed to simply reporting an event". Due to the distinct contexts in which de in confirmation cases are used, I suggest that de in these cases involve shi...de sentences with a silent shi, as shown in (33).

B: (upon finding the watch)

kan! shou-biao shi zai zhe de.

look watch FOC at here DE

'Look, the watch is here.'

This analysis is supported by the fact that shi may be pronounced in these sentences without any difference in discourse effects.

The current analysis supports a more nuanced view of the relation between bare $d e$ sentences and shi...de sentences with a silent shi, providing evidence for the existence of both these types of constructions (compare Li and Thompson 1981, Cheng 2008, Hole 2011). These two types of constructions are distinguished by the discourse environments they may appear in. Unlike a bare de sentence, the evidence for the proposition expressed by the prejacent in a shi...de sentence (with or without a silent shi) does not have to be private at speech time.

6. Summary and Implications. To summarize, I have made the following proposals regarding the semantics and syntax of sentence final $d e$ in a bare de sentence in Mandarin Chinese: (i) de marks the speaker's belief that the status of the evidence for the asserted proposition is private at utterance time; (ii) $d e \mathrm{P}$ is below TP and above $\operatorname{Mod}^{\mathrm{NE}} \mathrm{P}$.

The current analysis has implications on the syntax of modal auxiliaries, the relation between bare de sentences and shi...de sentences, and the syntax of discourse particles. With respect to the syntax of modal auxiliaries, the distribution of $d e$ in A-not-A questions provides a new kind of evidence in support of the claim that Mandarin epistemic modals occupy a structurally higher position than non-epistemic modals (Tsai 2015). The current analysis supports 
a more nuanced view of the relation between bare de sentences and shi...de sentences with a silent shi, providing evidence for the existence of both bare de sentences and shi...de sentences with a silent shi, and offering a new way to distinguish a true bare de sentence from a shi...de sentence with a silent shi. In terms of the syntax of discourse particles, the proposed analysis suggests the availability of two syntactic areas where discourse related particles may appear: one in the CP edge above items associated with sentence force (see for example Paul (2014)) and one in the clause medial area between TP and above $\operatorname{Mod}^{\mathrm{NE}} \mathrm{P}$. It connects de with sentence final $-l e$ in Mandarin, which has been argued to occupy a position below TP and above $\operatorname{Mod}^{\mathrm{NE}} \mathrm{P}$ (for nonepistemic modals) (Soh and Gao 2006; Erlewine, to appear, 2017). Like de, sentence final -le has been associated with discourse properties and has been noted to be a marker of "currently relevant state" (Li and Thompson 1981) and analyzed as involving speaker presupposition (Soh and Gao 2008; Soh 2008, 2009).

Finally, the current proposal connects de with discourse particles that mark the speaker's belief about whether the (evidence for the) asserted proposition is shared knowledge between the speaker and the hearer and whether the (evidence for the) proposition is "verifiable on the spot", such as German ja (Kratzer 1999, 2004; Gutzmann 2009) and English parenthetical I'm telling you (Reese and Soh 2018)). German discourse particle $j a$ (in its unstressed uses) requires that the asserted proposition be shared knowledge between the speaker and the addressee or verifiable on the spot (Kratzer 1999, 2004; Gutzmann 2009). ${ }^{5}$ Mandarin de and German ja thus appear to make reference to the same discourse features, but with opposite values. ${ }^{6}$ In Reese and Soh (2018), we show that English parenthetical I'm telling you is also sensitive to the same discourse features, sharing the same values with Mandarin de (see Reese and Soh 2018 for further discussion about the connection with German $j a$ ). Further comparisons between Mandarin de, German ja and English I'm telling you will likely contribute to clarifications about similarities and differences between these closely related discourse particles and the semantic parameters they operate on.

\section{References}

Cheng, Lisa Lai-Shen. 1991. On the typology of wh-questions. Cambridge, MA: MIT dissertation.

Cheng, Lisa Lai-Shen. 2008. Deconstructing the shi...de construction. Linguistic Review 25. 235266. https://doi.org/10.1515/TLIR.2008.007.

Cinque, Guglielmo. 1999. Adverbs and functional heads. Oxford: Oxford University Press.

Erlewine, Michael Yoshitaka. To appear. Sentence-final particles at the vP phase edge. In Proceedings of the $25^{\text {th }}$ North American Conference on Chinese Linguistics (NACCL 25).

Erlewine, Michael Yoshitaka. 2017. Low sentence final particles in Mandarin Chinese and the Final-over-Final Constraint. Journal of East Asian Linguistics 26. 37-75. https://doi.org/10.1007/s10831-016-9150-9.

\footnotetext{
${ }^{5}$ An earlier analysis by Lindner (1991) proposes that in using ja, the speaker indicates that in his/her eyes the proposition $\mathrm{p}$ is not controversial.

${ }^{6}$ There is a difference between Mandarin de and German ja in their current descriptions. The restriction is stated in terms of whether the evidence for the asserted proposition is private (not common knowledge and not verifiable on the spot) in case of de, while it is stated in terms of whether the asserted proposition is common knowledge or verifiable on the spot (not private) in case of $j a$.
} 
Ernst, Thomas. 1994. Conditions on Chinese A-not-A questions. Journal of East Asian Linguistics 3. 241-264. https://doi.org/10.1007/BF01733065.

Ernst, Thomas. 2009. Speaker-oriented adverbs. Natural Language and Linguistic Theory 27. 497-544. https://doi.org/10.1007/s11049-009-9069-1.

Gutzmann, Daniel 2009. Hybrid semantics for modal particles. Sprache und Datenverarbeitung 33. 45-59.

Huang, C.-T. James. 1982. Logical relations in Chinese and the theory of grammar. Cambridge, MA: MIT dissertation.

Huang, C.-T. James. 1988. Wo pao de kuai and Chinese phrase structure. Language 64. 274-311.

Hole, Daniel. 2011. The deconstruction of Chinese shi...de clefts revisited. Lingua 121.17071733. https://doi.org/10.1016/j.lingua.2011.07.004.

Li, Charles N \& Sandra A. Thompson. 1981. Mandarin Chinese: A functional reference grammar. Berkeley, CA: University of California Press.

Lindner, Katrin. 1991. 'Wir sind ja doch alte Bekannte' The use of German ja and doch as modal particles. In Werner Abraham (eds), Discourse particles: Descriptive and theoretical investigations on the logical, syntactic, and pragmatic properties of discourse particles in German,163-201. Amsterdam/Philadelphia, PA: John Benjamins.

Kratzer, Angelika. 1999. Beyond 'Ouch' and 'Oops'. How descriptive and expressive meaning interact. Comment on Kaplan's paper at the Cornell Conference on Context Dependency. March 26. http://semanticsarchive.net/Archive/WEwNGUyO/.

Kratzer, Angelika. 2004. Interpreting focus: Presupposed or expressive meanings? A comment on Geurts and Van der Sandt. Theoretical Linguistics 30. 123-136. https://doi.org/10.1515/thli.2004.002.

Law, Paul. 2006. Adverbs in A-not-A questions in Mandarin Chinese. Journal of East Asian Linguistics 15. 97-136. https://doi.org/10.1007/s10831-005-4916-5.

Lin, Jo-Wang. 1992. The syntax of zenmeyang 'how' and weishenme 'why' in Mandarin. Journal of East Asian Linguistics 1. 293-331. https://doi.org/10.1007/BF00130555.

Paul, Waltraud. 2014. Why particles are not particular: Sentence final particles in Chinese as heads of a split CP. Studia Linguistica 68. 77-115. https://doi.org/10.1111/stul.12020.

Reese, Brian \& Hooi Ling Soh. 2018. Parenthetical I'm telling you as a marker of private evidence. Paper presented at the 92 Annual Meeting of the Linguistic Society of America, Salt Lake City.

Soh, Hooi Ling. 2007. Ellipsis, Last Resort, and the dummy auxiliary shi 'be' in Mandarin Chinese. Linguistic Inquiry 38. 178-188. https://doi.org/10.1162/ling.2007.38.1.178.

Soh, Hooi Ling \& Meijia Gao. 2006. Perfective aspect and transition in Mandarin Chinese: An analysis of double -le sentences. In Pascal Denis, Eric McCready, Alexis Palmer, and Brian Reese (eds.), Proceedings of 2004 Texas Linguistics Society conference:Issues at the semantics-pragmatics interface, 107-122. Somerville, MA: Cascadilla Press.

Soh, Hooi Ling, and Meijia Gao. 2008. Mandarin sentential -le, perfect and English already. In Johannes Dölling, Tatjana Heyde-Zybatow, and Martin Schäfer (eds.), Event Structures in linguistc form and interpretation, 447-473. Berlin: Mouton de Gruyter.

Soh, Hooi Ling. 2008. The syntax and semantics of change/transition: Evidence from Mandarin Chinese. In Susan Rothstein (ed.), Theoretical and cross-linguistic approaches to the semantics of aspect, 387-419. Philadelphia, PA: John Benjamins.

Soh, Hooi Ling. 2009. Speaker presupposition and Mandarin Chinese sentence final -le: A unified analysis of the "change of state" and the "contrary to expectation" reading. Natural 
Language and Linguistic Theory 27. 623-657. https://doi.org/10.1007/s11049-009-90744.

Song, Wei. 2015. The sentence final de and the post-verbal de in the shi...de construction in Mandarin Chinese. Minneapolis, MN: University of Minnesota MA Plan B paper.

Stalnaker, Robert. 1999. Context and content: Essays on intentionality in speech and thought. Oxford: Oxford University Press.

Stalnaker, Robert. 2002. Common ground. Linguistics and Philosophy 25. 701-721. https://doi.org/10.1023/A:1020867916902.

Tsai, Wei-Tien Dylan 2015. On the topography of Chinese modals. In Ur Shlonsky (ed.), Beyond functional sequence: The cartography of syntactic structures, volume 10, 257-294. Oxford: Oxford University Press. 